\title{
Considerations about recovery of critical metals using bio-metallurgy
}

\author{
Săndica Liliana Gherghe ${ }^{1, *}$ \\ ${ }^{1}$ National Research and Development Institute for Nonferrous and Rare Metals, 102 Biruintei Blvd, Pantelimon; Romania
}

\begin{abstract}
The increased requirement of critical metals due to green technologies needs, together with the geopolitical environment to ensure these metals, has entailed decisive measures to avoid current supply insecurities in each country. These metals are essential to the products and services made and used daily, and contribute to sustaining and growing the economy. Thus, sustainable approaches from technological, environmental, economic and social point of view are needed to recover these metals from different resources. By using resources more efficiently, innovating in the concept of circular economy, it can be assure re-using, re-manufacturing or recycling of valuable materials. In this paper are presented some considerations related to using the waste dumps as potential resources to obtain critical metals by biometallurgical processes.
\end{abstract}

\section{Introduction}

The metals are precious raw materials to the economy of any country and need to be secured for sustainable production of key components of various products such vehicle production, electronics and IT hardware, low carbon energy technologies, mechanical, electrical and process engineering.

The availability and supply of critical metals has a significant influence on the economy of any country by affecting manufacturing, export, and job creation. Most of the critical and rare metals are currently obtained through mining of primary sources, which are finite, unequally distributed in the world, and rapidly decreasing as a result of high consumption due to urbanization, increasing standards of living, and the population explosion. Therefore, it is an urgent need to source these critical and scarce elements from alternative sources using sustainable technologies. Potential alternate sources that are intensely considered include recycling from end-of-life metal wastes and recovery from mine tailings and wastewaters [1].

Continue and rapid increase of the waste materials generation and wide range of industrial applications with high-tech technologies sustain the assessment and development of innovative technologies focus on waste recycling. Biometallurgical technologies are most likely to find their niches in recovering critical metals from these waste residues. The efficacy of biometallurgical recovery of metals from waste dumps depends largely on the matrix composition and chemical species of the targeted metals in the wastes [2].

Some wastes can become valuable resources, supplying metals that are extracted today by other processes, promoting recycling, minimizing harmful waste and hazard and dissipation.

Biotechnological recovery of critical and scarce metals has received significant interest because it can be used to treat diluted wastes and required low energy input [1].

Technology is crucial to improve recycling processes and to trace and capture secondary raw materials [3].

\section{Criticality assessment}

Critical raw materials (CRM) are raw materials of high importance to the economy of the EU and whose supply is associated with high risk.

The development of European economy depends decisive on access to CRM. The important topic on CRM include strong and growing demand from industry as well as limited and volatile supply. The closed circuit of the suppling of raw materials potentially constrains economic growth as rising prices make key industries less profitable. In the worst cases, severe shortages of CRM may also determine even temporary production halts. This is something that could conceivably have significant negative repercussions for the competitiveness of European industry. The EU's supply of CRM is further threatened by the fact that some emerging economies, in particular China, are limiting raw materials supply by means of export restrictions [4].

The European economy is the largest in the world, with a strong industry, while the mineral production within EU does not satisfy the demand. Therefore, it lacks the mineral wealth needed to sustain the growth. The problem of addressing challenges with the minerals supply, especially concerning certain CRM, has arisen

\footnotetext{
* Corresponding author: gliliana@imnr.ro
} 
with recent market volatility that is partly a result of dependency on certain countries.

The two main parameters, economic importance (EI) and supply risk (SR), are used to determine the criticality of the material for the EU. In the revised methodology for criticality assessment, the availability of substitutes is considered a reducing element in both the economic importance and the supply risk dimensions. The assessment only takes into account the proven substitutes that are readily available today and able to reduce the consequences of a disruption and/or influence the risk of a disruption. Commercial information and published patents are only used to identify proven substitute alternatives readily available and applicable at the market today. 'Substitutability' and 'potential future substitution' are not considered in this methodology [5].

The factors of criticality related to supply and demand of metals are presented in table 1 [6].

Table 1. The factors of criticality related to supply and demand of metals.

\begin{tabular}{|l|l|}
\hline $\begin{array}{c}\text { SUPPLY } \\
\text { Indicators for evaluating } \\
\text { supply risk }\end{array}$ & $\begin{array}{c}\text { DEMAND } \\
\text { Indicators for evaluating } \\
\text { vulnerability }\end{array}$ \\
\hline Country concentration & Value of products affected \\
\hline Country risks & Spread of utilization \\
\hline Depletion time & Strategic importance \\
\hline By-product dependency & $\begin{array}{l}\text { Value of the utilized } \\
\text { material }\end{array}$ \\
\hline Proved substitute & Proved substitute \\
\hline Import dependence & Demand share \\
\hline Price volatility & Import dependence \\
\hline
\end{tabular}

The increasing competition for resources, price volatility and potential interruptions in supply, caused by a combination of growing worldwide demand, concentration of supply in a few countries, trade restrictions in sometimes, lack of currently viable alternatives in key applications are the key factors in the supply response to increased demand [7].

There are several worldwide changes underway that are likely to make resource extraction from alternative sources a more and more viable option such as rapidly growing competition for resources, increasing raw material prices, the large-scale environmental problems We now face and the fact that the natural reservoirs for many valuable resources are rapidly declining [8,9]. At the same time, several studies belonging to the research field of industrial ecology show that in many regions of the world massive amounts of strategically important materials such as metals have accumulated in landfills $[10,11,12]$. The potential for resource recovery from landfills appears significant, but depend of the performance of current technologies. In the past, the metals obtaining efficiency was not so high for some metals from some raw material and, as a consequence, important amount of such metals was discharged in tailing dams. Therefore, the mining industry has been generated waste dumps on the surface of natural terrains and caused major problem in the context of environmental protection.

Some metal-bearing and liquid wastes are considered as secondary sources of critical and scarce metals.
One measure to mitigate the criticality is recycling. Recycling is effective for the metals whose: "Criticality" is high and "Potential of recycling" is high. The "potential of recycling" of a metal depend on the "amount of metal contained in the waste-products in one country" and "the amount of the metal's demand in the same country: "Potential of recycling" of a metal =

Amount of a metal contained in the waste - products in the country Amount of the metal's demand in the contry

In the assessment of the criticality, the following factors and influences are taken into account:

- technical performance (extent to which the substitute can replace the functionality of a candidate raw material in an application)

- cost performance (costs often drive decisions in business);

- substitute production (availability of substitutes in sufficient quantities need to be considered);

- substitute criticality (substituting one critical material with another is unlikely to decrease the RM supply risk in a given application). It is important to to assess the criticality of the substitute itself. If a substitute material is already critical, it might not be readily available as a substitute option.

- substitute by-/co-production (if the proposed substitute is mainly obtained as a by- or co-product, its supply is dependent on a demand for another raw material) [5].

Table 2. List of today critical raw materials at EU level.

\begin{tabular}{|l|l|}
\hline No & Raw material \\
\hline 1 & Antimony (Stibium) \\
\hline 2 & Beryllium \\
\hline 3 & Borates \\
\hline 4 & Chromium \\
\hline 5 & Cobalt (Cobaltum) \\
\hline 6 & Coking coal \\
\hline 7 & Fluorspar (Fluorite) \\
\hline 8 & Galium \\
\hline 9 & Germanium \\
\hline 10 & Indium \\
\hline 11 & Magnesite \\
\hline 12 & Magnesium \\
\hline 13 & Natural graphite \\
\hline 14 & Niobium \\
\hline 15 & Phosphate rock \\
\hline 16 & Platinum Group Metals \\
\hline 17 & Heavy Rare Earth Elements \\
\hline 18 & Light Rare Earth Elements \\
\hline 19 & Silicon metal (Silicium) \\
\hline 20 & Tungsten (Wolframium) \\
\hline
\end{tabular}

Taking into account the analysis performed by experts at European level, a list of 14 critical metals has been established in 2010. Due to the fact that the criticality's degrees changed over the time, the list has been up-dated with six new materials (marked in grey in table) at 20 critical metals in 2014 [13, 14]. This new list includes thirteen of the fourteen materials identified in the previous report, with only tantalum (due to a lower supply risk) moving out of the EU critical material list. Within the framework of the EU Raw Materials Initiative, it was 
decided to assess and up-date the number of raw materials at least every three years.

\section{Why bio-processes?}

Microbes interact with metals and minerals in natural and synthetic environments, altering their physical and chemical state; on the other-hand metals and minerals are also able to affect microbial growth, activity and survival. Many minerals have biogenic genesis, and the formation of such biominerals has a geological and industrial significance, as well as providing important structural components for many organisms.

Microorganism can decisively influence the redox chemistry of minerals and therefore, could have an important effect for the extraction and processing of valuable metals.

Many microorganisms and methods are described in the literature as potential options for metals recovery/recycling, but the efficiency of these processes depends not only on the activity of the microorganisms, but also on the geochemical composition of the resources.

Naturally occurring microorganisms can sorb a variety of $P G M s$, REEs and heavy metals, including $P t$, $\mathrm{Fe}, \mathrm{Ni}, \mathrm{Cu}, \mathrm{Zn}, \mathrm{Pb}, \mathrm{Cu}, \mathrm{Pd}, \mathrm{Ag}, \mathrm{Cd}, \mathrm{Pt}, \mathrm{Au}$, and $\mathrm{Hg}$, with binding capacities typically on the order of $10^{-5}-10^{-3} \mathrm{~mol}$ metal $\mathrm{g}^{-1}$ (dry wt) microbe [2]. The metal's chemical species influence the reduction potential and uptake efficiency.

The metals biosorption to microbes can involve a variety of processes, including absorption, ion exchange, complexation, and precipitation $[15,16]$. These processes are determined by the chemical groups displayed on the extracellular surfaces of microbial cells, such as carboxyl, phosphoryl, hydroxyl and carbonyl.

The competition between ions changes in the activities of metals and/or microbial functional group, or changes to the electrical layer at the microbe-water interface is influenced by essential biological parameters $(\mathrm{pH}$, ionic strength and temperature). The reduction in heavy metal uptake on Gram negative bacteria with increasing ionic strength has been attributed to changes in the activity of metal cations [17].

Most studies performed are focused on the removal of the metals from the wastewaters. Bioaccumulation is a metabolically active process in living organisms that works through adsorption, intracellular accumulation, and bioprecipitation mechanisms, individual and/or in consortia. Internal metal accumulation and/or metal biosorption by metal resistant microorganisms should be clear understand for each study case.

Biomining is often used for the processing of ore and concentrates and both bacteria and fungi are used in bioleaching [18]. A variety of microorganisms is found in leaching environments and has been isolated from leachates and acidic mine drainage. Although environmental conditions are usually described as being extreme and aggressive due to very low $\mathrm{pH}$ values and high metal concentrations, these systems can show high levels of microbial biodiversity [19]. Recent detailed investigations based on molecular methods revealed that microbial bioleaching communities are composed of a vast variety of microorganisms resulting in complex microbial interactions and nutrient flows. The composition of these communities is usually subjected to seasonal fluctuations and may vary between different mining locations and, in addition, organisms are not homogeneously distributed over the whole leaching environment [20]. Different biological materials, such as bacteria, algae and fungi have been received high attention for metals removal and recovery, due to their good performance, low cost and large available quantities. These microorganisms have metal-sequestering property and can be used to decrease the concentration of some metals ions in solution from ppm o ppb level. It can effectively sequester dissolved metals ions out of dilute complex solutions with high efficiency and quickly, therefore it is recommended for the treatment of high volume and low concentration complex wastewaters [21].

Better understanding of biological role of REEs and their acquisition by microorganisms will allow the development of bio-recovery of REEs from solid/liquid wastes.

Microbial reduction of soluble tellurite to insoluble elemental $T e$, represent a critical step in Te recovery.

Among $P G M s$, the major economic importance has $\mathrm{Pt}$, $\mathrm{Pd}$ and $\mathrm{Au}$ [22]. Paladium has been obtained using diverse microorganisms and biofilms [23]. The platinium recovery by mixed culture has been demonstrated [24].

The Leucobacter chromiiresistens have been isolated and identified a strain of resistant to chromium [25].

The $\mathrm{T}$. ferrooxidans accelerates the leaching of gallium, and indium is also solubilized. T. ferrooxidans also oxidizes chemically pure gallium and $\mathrm{Ga}_{2} \mathrm{~S}_{3}$ associated with chalcopyrite concentrates, simultaneously by direct and indirect mechanisms.

Germanium, which replaces in isomorphic manner the $\mathrm{Cu}, \mathrm{Zn}$ and $\mathrm{Pb}$ in the respective sulphides, can be leached by $\mathrm{T}$. ferrooxidans within a wide range of $\mathrm{pH}$. The rhenium present in molybdenite, pyrite, chalcopyrite and galena deposits is also dissolved in concentrations from 5 up to $500 \mathrm{mg} \mathrm{L}^{-1}$. Some inorganic selenium compounds are oxidized/reduced by microorganisms [26].

One strain of Penicillium tricolor is capable of lowering the value of the $\mathrm{pH}$ from the culture medium from 10.0 to 3.0 and it can also be used to leach out $R E E$ and radioactive elements [27].

Metal bioaccumulation was studied in some microorganisms, especially for $U$ (Rhodanobacter $\mathrm{sp}$. described by Sousa et al., 201315) but also for $\mathrm{Th}, \mathrm{Co}, \mathrm{Cr}$, $\mathrm{Mn}, \mathrm{Sn}$ and Pt. Nanoparticles and granular biosorbents [28] were developed for water remediation, capable of agglomerating heavy metals by adsorption $\mathrm{Ag}, \mathrm{Cd}, \mathrm{Cu}$, $\mathrm{Pb}, \mathrm{Zn}$ and $\mathrm{U}$. The process seems versatile and likely to have future expansion [29].

Proteus vulgaris can absorb cobalt, with a high efficiency under conditions of neutral $\mathrm{pH}$ and Saccharomyces cerevisiae can accumulate cadmium and cobalt $[30,31]$.

Tungsten and molybdenum causes changes in the bacteria Desulfovibrio vulgaris, because they are involved in activation of some specific enzymes [32]. 
The main applications of bioleaching are being used commercially for the recovery of copper, uranium and gold [33].

\section{Bio-metallurgy: a way for future}

The development of an EU strategy on raw materials emphasizing the concept of the "added value chain", pursuing the three-pillar strategy to: (1) ensure the fair and sustainable supply of raw materials from international markets, promoting international cooperation with developed and developing countries; (2) foster sustainable supply of raw materials from European sources, and (3) reduce consumption of primary raw materials by increasing resource efficiency and promoting recycling [34]. The above drivers serve as a backdrop rationale for the development of the innovative hybrid technologies, applicable in primary and secondary sources of raw materials.

Biotechnological recovery has received interest because it can work with dilute waste streams and requires a low energy input. In the last years, microbe-metal interactions have received renewed attention as a route to develop sustainable biotechnological metal-recovery processes for leaching from low-grade ores and solid wastes as well as via metal immobilization from leachate solutions, process streams, and wastewaters [1].

Bio-extractive methods complete the alternative approaches for extracting metals from different primary and secondary resources. The main aspects of biological processes are related to long time required to obtain economic levels of metal extraction (from days to years sometime) and concerns about unexpected behaviour of biological system involved. On the other hand, biological processes involve much lower temperature, smaller carbon footprint and could be an option for pretreatment of low-grade and/or complex primary and secondary resources for metals recovery [35].

Besides the metals recovered in the leachate, there is increasing interest in the insoluble metals left in the residues. Inferior lead sulfide concentrates can be transformed into high-value concentrates by leaching of metals (e.g., zinc, cadmium, copper) that interfere with conventional processes for the recovery of the lead. Similar procedures are being investigated for the extraction of silver and other precious metals that are finely disseminated in iron, arsenic, copper and zinc sulfides. The metal sulfides are first removed by microbial leaching and the precious metals are then recovered from the residue.

Traditionally raw materials exploitation is focused in high grade ore deposits, extracted and processed by conventional techniques, pyro and/or hydrometallurgy. The metal recovery efficiency of these techniques was variable along time and framed by a minimum efficient scale approach. As a consequence, a significant amount of metals was discarded to tailings dams, many of those in concentrations that exceed today's mines cut-off grades. Tailings from mining and metallurgical processes put some very serious environmental problems because of their metals content and have raised questions about safe disposal.

The bioleaching will become more important for zinc, nickel, cobalt and molybdenum recovery. Investment and operating costs are much lower than for conventional pyrometallurgical and hydrometallurgical processes. The processing plant can be built in the immediate vicinity of the ore deposit, saving transport costs. The procedures are not complicated and are easy to control, extensive technical knowledge is not required [36].

The studies and researches on bioleaching of high tech critical metals are at the beginning. The bioleaching processes are influenced by a wide range of parameters including physicochemical and microbiological factors, which can affect both the growth of the microorganisms and their behavior during biological processes. The optimal growth conditions for microorganisms must be maintained in order to assure the resistance of microbes to the metals and get a good efficiency of bioprocesses. [37].

\section{Conclusions}

There is a demand for less expensive and more environmentally friendly processes, with developments on both technical and biological issues.

A crucial aspect is related to increasing the rate of leaching and the tolerance of the microorganisms/consortia to different metals, in different types of primary/secondary materials. Biotechnological processes are already being applied at industrial scale in biomining of sulfidic ores and the treatment of wastewaters containing metals.

A little progress has been made in the development of biotechnological processes for the recovery of critical and scarce elements. Therefore, there are few or no studies on metal-microbe interactions for most critical elements. The importance of biotechnologies has to be taken into account due to the ability of microorganisms to selectively sequester diffuse elements (e.g. critical metals) from different solid/liquid wastes. This is starting point of challenges for next years, for development of new processes for the extraction and recovery of metals secondary resources such as mine tailings, stored solid wastes, end-of-use products, sewage sludge, process streams, and industrial effluents using microorganism's abilities. Present challenges faced in biological recovery include selectivity, low $\mathrm{pH}$, and the presence of salts and/or other metal co-contaminants.

Progress in the development and integration of biological processes and biological recovery with hydrometallurgy methods will foster the development of novel biotechnological processes for extraction and recovery of critical metals [1].

By combining future valorization of different materials with energy production and land re-use, cost efficient resource recovery of landfills will generate economic, environmental and social issues. As primary resources become scarcer enhanced landfill mining will become more feasible. However, strategic policy decisions and tailored support systems for enhanced landfill mining is sustained by standardized life cycle 
assessment frameworks and will be indispensable to remove the remaining non-technical barriers [37].

The last worldwide changes and recent research findings indicate the emergence of a new perspective on landfills as reservoirs for resource extraction.

The author would like to acknowledge the financial support from the Romanian National Authority for Scientific Research and Innovation (UEFISCDI), project number 16/2016, within ERA-MIN Program.

\section{References}

1. Y. V. Nancharaiah, S. V. Mohan, P. N. L. Trends Biotechnol., 34, No.2, (2016)

2. W-Q. Zhuang, J. Fitts, C. Ajo-Franklin, S. Maes, L. Alvarez-Cohen, T. Hennebel, Curr. Opin. Biotechnol, 33, 327-335, (2015)

3. F. J. Dessart, L. Bontoux, Non-ferrous Metals Manufacturing: Vision for 2050 and Actions Needed, JRC Science for Policy Report, (2017)

4. European Parliament - Directorate General for Internal Policies, Substitutionability of Critical Raw Materials, (2012)

5. European Commission, Methodology for establishing the EU list of Critical Raw Materials, (2017)

6. Mitsutaka M., Criticality assessment and R\&D for circulation of critical materials, The 6th Trilateral EU-US-Japan Conference on Critical Materials BREYDEL, (2016)

7. Department for Environment, Food and Rural Affairs, (2012)

8. Halada, K., Ijima, K., Shimada, M., Katagiri, N., J JPN I MET, 73, 151-160, (2009)

9. Kapur, A., Progress of J Ind Ecol, 3, 209-236, (2006)

10. Lifset, R.J, Gordon R.B., Graedel T.E., Spatari S., Bertram M., JOM 54, 21-26, (2002)

11. Kapur A., Graedel T.E., Envir Sci and Tech, 40, 3135-3141, (2006)

12. Muller D., Wang T., Duval B., Graedel T.E., PNAS 103, 16111-16116, (2006)

13. European Commission, Critical Raw Materials for the EU, (2010)

14. European Commission, Report on critical raw materials for the EU, (2014)

15. G. M. Gadd, J. Chem. Technol Biotechnol, 84, 13-28, (2009)

16. H. Moriwaki, H. Yamamoto, Appl. Microbiol Biotechnol, 97, 1-8, (2013)

17. D. M. Borok, J. B. Fein, J Colloid Interface Sci, 286, 110-126, (2005)

18. A. Schippers, S. Hedrich, J. Vasters, M. Dobre, W. Sand, S. Willscher, Adv Biochem Eng Biotechnol, 141, 1-47, (2014)
19. J. B. Glass, H. YU, J. A. Steele, K. S. Dawson, S. Sun, K. Chourey, C. Pan, R. L. Hettich, V. J. Orphan, Environ. Microbiol. 16, 1592-1611, (2014)

20. H. Zhiguo, G. Fengling, Z. Jiancun, H. Yuehua, Q. Guanzhou, FEMS Microbiol. Ecol, 74, 155-164 (2010)

21. J.L. Wang, C. Chen, Biotechnol Adv, 24, 427-51, (2006)

22. C. N. Mpinga, J. J. Eksteen, C. Aldrich, L. Dyer, Miner Eng, 78, 93-113, (2015)

23. A. Pat-Espadas, J. A. Field, E. Razo-Flores, F. J. Cervantes, R. Sierra-Alvarez, J. Chem. Technol. Biotechnol, 91, 4, (2016)

24. S. Maes, R. Props, J. P. Fitts, R. De Smet, R. VilchezVargas, M. Vital, D. H. Pieper, F. Vanhaecke, N. Boon, T. Hennebel, Environ. Sci. Technol, 50, 5, 2619-2626, (2016)

25. G. Sturm, J. Jacobs, C. Sproer, P. Schumann, J. Gescher, Internat. J. of System and Evol, Microb, 61, 956-960, (2011)

26. Henry Lutz Ehrlich, Geomicrobilogy, Fourth edition, Chapter 20, 669-682, (2002)

27. Y. Qu, B. Lian, B. Bioresour Technol, 136, 16-23, (2013)

28. T. Raychoudhury, T. Scheytt, Water Sci Technol, 68, 7, 1425-39, (2013)

29. BioCriticalMetals project developed within ERAMIN Program (2016-2019).

30. M. Neyland, P. Dunkel, AL Schade, J. of. Gen. Microbiology, 7, 409-416, (1952)

31. P. R. Norris, J. of Gen. Microbiology, 99, 317 - 324, (1977)

32. S. M. Da Silva, J. Voordouw, C. Leitao, M. Martins, G. Voordouw, IAC Pereira, Microbiology, 159, 1760-1769, (2013)

33. K. Bosecker, FEMS Microbiol Rev., 20, 591-604, (1997)

34. Communication from the European Commission to the European Parliament and the Council, The Raw material initiative-meeting our critical needs for jobs and growth in Europe, COM (2008) 699 final.

35. D. Barrie Johnson, Curr. Opinion in Biotech, 30, 24$31,(2014)$

36. F. Acevedo, J. C. Gentina, S. Bustos, J. Biotechnol, 31, 115-123 (1993)

37. A. Monballiu, N. Cardon, M. T. Nguyen, C. Cornelly, B. Meesschaert, Y. W. Chiang,

38. Bioinorg Chem Appl, (2015)

39. P. T. Jones, D. Geysen, Y. Tielemans, S. V. Passel, Y. Pontikes, B. Blanpain, M. Quaghebeur, N. Hoekstra, J Clean Prod, 55, 92-102, (2013) 